\title{
Educational Role of Nurses to Patients who have Experienced an Acut Cardiac Event: A Pilot Study in Albania
}

\author{
Msc.Valbona Alliu' ${ }^{1}$, Phd. Alketa Hoxha (Qosja) ${ }^{2}$, Prof. Petrit Bare ${ }^{3}$ \\ ${ }^{1,2}$ University of Medicine, Faculty of Technical Medical Sciences, Tirana, Albania \\ ${ }^{3}$ Cardiologist, Dean of Faculty of Technical Medical Sciences, University of Medicine, Tirana, Albania
}

\begin{abstract}
Background: The significant role of integrating education in a rehabilitation programme has been widely acknowledged by all health professionals. Therapies that have been shown to reduce these risks (secondary prevention of modifiable risk factors) continue to be underutilized. Cardiac educational programs are intended to prevent the recurrence of cardiac event and improve patients' quality of life. However, patients' information requests have historically not been well met by physicians and nurses in Albania. Aim: This study aimed to evaluate the impact of nursing education of patients, who have experienced an acute cardiac event, about modifiable risk factors of cardiovascular diseases. Methods: This is a descriptive study. We recruited 100 patients after a cardiac event, between the ages of 33-78 years. Self-report questionnaires, which included general characteristics, disease-related characteristics and a pre-test/post-test design was conducted to assess needs of the patients, changes in knowledge and self-care abilities. Results: We found that more than 90\% of patients desired information, particularly about heart failure symptoms, time to notify healthcare providers, prognosis, and exercise/physical activity. Of the 100 participants $61 \%$ were male, 59\% were aged between 55 and 74 years, and $31.6 \%$ had not completed ten years education. There were significant statistically differences between the responses in the first test and the second test referred to: smoking[95\% CI: 1.055-1.738, $p<0.05]$, hypertension stabilized[95\% CI: $0.678-1.00, p \leq 0.05]$, regular health checkup[95\% CI: 0.179-0.392, $p<0.05$ ], stress in family[95\% CI: 0.861-1.815, $p>0.05]$, no exercise[95\% CI: 1.791-4.015, $p<0.05]$ and healthy nutrition[95\% CI: 0.493-0.918, $p<0.05]$. Both women and men evidenced significant improvements in their diet, exercise, blood pressure, quality of life and stress management practices, which they maintained over the 6 months of the study. There was a statistically significantly difference in the pre- and post-test scores for knowledge $(p<0.05)$. Conclusions: There is a lack of good level of knowledge among patients after an acute cardiac event. Implementing aggressive educational strategies is of utmost importance in Albanian population for preventing the rising prevalence of these diseases. Relevance to clinical practice: This pilot study has indicated that a patient-centre educating is beneficial and is associated with an improvement in patients' knowledge and self-care abilities. Healthcare professionals should utilize all educational resources specifically designed to the educational needs of these patients.
\end{abstract}

Keywords: nurse, education, cardiac event, self-care abilities, rehabilitation, modifiable risk factors.

\section{Introduction}

Rapid urbanization and adoption of sedentary life style resulted in a rising burden of cardiovascular diseases in the developing world. Awareness of risk factors of cardiovascular diseases varies among different populations ${ }^{[1-}$ 3]

Cardiac rehabilitation programmes, the most typical form of secondary prevention programme, are utilized by less than $30 \%$ of those eligible. Cardiovascular disease (CVD) is one of the most preventable causes of death in the world, due to the fact that the majority of its risk factors are preventable or controllable, such as hypertension, dyslipidemia, diabetes, obesity, smoking, lack of physical activity, stress, unhealthy dietary practices and diabetes ${ }^{[4,5]}$.

Patient education is key in order to detecting changes in body weight or clinical status early enough to allow the patient or a healthcare provider an opportunity to institute treatments that can prevent clinical deterioration in those patients $^{[5,6]}$. The main goal of cardiac rehabilitation is to prompt patients participate in their therapeutic treatment regimen to such an extent that they can achieve living almost a normal life. Cardiac rehabilitation programs comprising prescriptive exercise, health education, and counseling, yield compelling improvements in cardiac morbidity and mortality of participants ${ }^{[7-9]}$. The goals of heart failure patient education are to help patients and their caregiver(s) acquire the knowledge, skills, strategies, problem solving abilities, and motivation necessary for adherence to the treatment plan and effective participation in self-care ${ }^{[10]}$.

Secondary prevention incorporates identifying, treating, and rehabilitating patients with coronary heart disease or acute myocardial infarction to reduce their risk of recurrence, decrease their need for interventional procedures such as coronary artery bypass surgery, improve quality of life, and extend overall survival. Secondary prevention strategies include smoking cessation, blood pressure control, lipid management, physical activity promotion, weight management, diabetes management, antiplatelet agent/anticoagulant use, and long-term use of angiotensinconverting enzyme inhibitors and beta-adrenoceptor blockers $^{[11]}$

The most effective way to combat the epidemic of cardiovascular diseases in low income countries is its prevention. Awareness regarding modifiable risk factors of cardiovascular diseases has been identified as an important pre requisite for behaviour change and is often intended by the prevention programmes ${ }^{[12,13]}$. Although awareness alone is not sufficient yet it can be assumed to be an important component of behaviour change for decision making. 


\section{International Journal of Science and Research (IJSR) \\ ISSN (Online): 2319-7064 \\ Index Copernicus Value (2013): 6.14 | Impact Factor (2014): 5.611}

The significant role of integrating education in a rehabilitation programme has been widely acknowledged by all health professionals. Education is the process of acquiring knowledge and skills that can lead to changes in human behavior, necessary for the maintenance or improvement of health ${ }^{[14]}$. Given the fact that hospital stay is minimizing, neither health professionals nor patients have adequate time to devote to their education, consequently, education should start immediately after the diagnosis of the disease. A lot of changes were in our country during transition period and the major transitions have had apparent influences on behavioural, social, and lifestyle patterns.

\section{Aim}

This study aimed to evaluate the impact of nursing education of patients, who have experienced an acute cardiac event, about modifiable risk factors of cardiovascular diseases.

\section{Methods}

A descriptive study was performed in Polyclinic Nr.10 in Tirana, state polyclinic. This survey was conducted during the period from January 1,2014 to December 30, 2015, a period of 24 months. Ethical approval for this study was obtained from the Faculty of Technical Medical Sciences, University of Medicine, Tirana, Albania.

Patients, who had passed an acute heart attack, were contacted and given an explanation with regard to the purpose of the study. They were free to refuse participation in the study. Data were collected anonymously via selfadministered questionnaire. Those who agreed to take part in the study were given the questionnaires which were completed anonymously.

Moreover, confidentiality of the information was assured to them. All those patients who were mentally retarded and patients who refuse to participation in the study were excluded from the study.

Components of the questionnaire were based on already published studies ${ }^{[12,13,15]}$. The instrument was translated from English to Albanian language using translation-backtranslation procedure done by two independent translations. It mainly contained closed ended questions.

Demographic information collected included age, gender and education (no high school, some high school, high school graduate, some college, college graduate, or postgraduate).

Questions regarding knowledge of cardiovascular risk factors were collected as follows: data on participants' lifestyle, including their adherence to dietary regimens recommended by their physicians (regularly, occasionally, not at all), data on adherence to physical activity schedules recommended by their physicians (regularly, occasionally, not at all), and smoking habits (yes, no, stopped smoking after acute cardiac event, lipid profile (total cholesterol, lowdensity lipoprotein cholesterol, high-density lipoprotein, cholesterol, triglycerides), body mass index (BMI) and blood pressure. Those who could identify three out of these risk factors were considered to have good level of knowledge.

We recruited 100 patients with heart failure between the ages of 33-78 years. The intervention incorporated principles of social learning theory. After receiving a standardized message from their physicians, patients met with a nurse for about 1 hour. They were shown a 20 -minute videotape, given a leaflet and discussed about new lifestyle. No further intervention occurred after 12 months. Another interview was conducted after 12 months and patients given the same questionnaire.

\section{Statistical Analysis}

Data was analysed for frequencies and percentages using SPSS-19. Continuous variables like age and monthly income were mentioned as Mean \pm SD. Associations of educational status and gender with knowledge were assessed using chisquare test. Relative risk and 95\% confidence intervals were estimated by Poisson regression with robust error variance. A $p$ value of $<0.05$ was considered to indicate statistical significance.

\section{Results}

A total of one hundred eligible patients participated in the study. The same patients were interviews at least 6 months after the first interview.

Among them $61(61 \%)$ were males, while 39 (39\%) were females. The mean age of the man patients was $46.45 \pm 11.12$ years and the mean age of the female patients was $45 \pm 10.77$ years.

The $32(32 \%)$ patients were primary education, $40(40 \%)$ intermediate and $28(28 \%)$ were graduates.

It was found that mean weight of 61 male patients $(67.76 \pm 17.62)$ was higher than mean weight of 39 female patients $(59.7 \pm 13.79)$.

$15(15 \%)$ were between the age group $30-40$ years, 26 $(26 \%)$ were between $40-50$ years,

$29(29 \%)$ were between 50-60 years and $30(30 \%)$ were above 60 years of age[Table 1].

Table 1: Demographic characteristics of the study group

\begin{tabular}{|l|l|l|}
\hline Demographic Characteristics & Frequency & Percent \\
\hline Gender & 61 & $61 \%$ \\
\hline Male & 39 & $39 \%$ \\
\hline Female & 15 & $15 \%$ \\
\hline Age & 26 & $26 \%$ \\
\hline $30-40$ years & 29 & $29 \%$ \\
\hline $40-50$ years & 30 & $30 \%$ \\
\hline $50-60$ years & 32 & $32 \%$ \\
\hline$>60$ years & 40 & $40 \%$ \\
\hline Education & 28 & $28 \%$ \\
\hline$<10$ years
\end{tabular}

Volume 5 Issue 1, January 2016 www.ijsr.net 


\section{International Journal of Science and Research (IJSR) \\ ISSN (Online): 2319-7064}

Index Copernicus Value (2013): 6.14 | Impact Factor (2014): 5.611

Table 2: Frequency and percentage distribution of risk factors of patients involved in the study

\begin{tabular}{|l|l|}
\hline Risk factors & Frequency (n, \%) \\
\hline Smoking & $6464 \%$ \\
\hline Alcoholism & $5151 \%$ \\
\hline Diagnosed with hypertension & $4242 \%$ \\
\hline Diagnosed with diabetic mellitus & $3939 \%$ \\
\hline Family history of cardiac disease & $1919 \%$ \\
\hline Absence of regular exercises & $7676 \%$ \\
\hline Feel depressed most of the time & $5959 \%$ \\
\hline Live in urban community & $100100 \%$ \\
\hline Problems with sexual life & $4545 \%$ \\
\hline Attending regular medication check ups & $2121 \%$ \\
\hline
\end{tabular}

\section{Risk factors of patients involved in the study}

(n.)

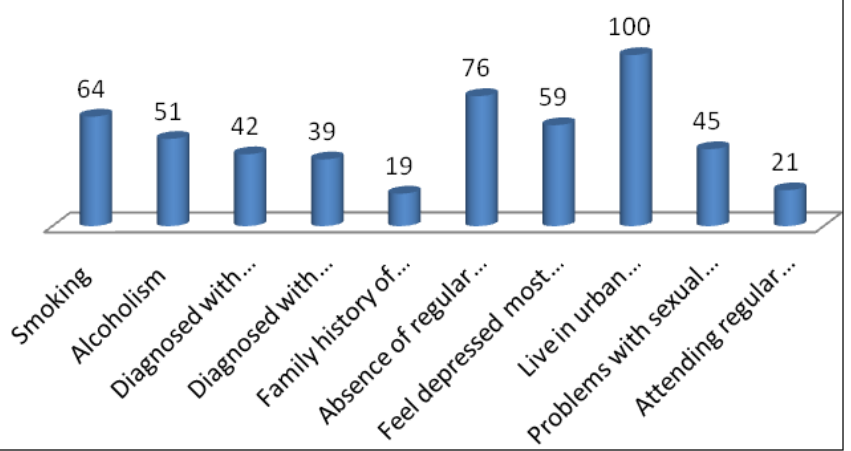

Figure 1: Frequency and percentage distribution of risk factors of patients involved in the study

Table 3: Frequency distribution of risk factors of participants (first interview)

\begin{tabular}{|c|c|}
\hline Risk factors of participants & Frequency (n, \%) \\
\hline Smoking & $6565 \%$ \\
\hline Hypertension Stabilized & $6161 \%$ \\
\hline Regular Health Checkup & $2121 \%$ \\
\hline Stress in Family & $4040 \%$ \\
\hline No Exercise & $5959 \%$ \\
\hline Healthy Nutrition & $3737 \%$ \\
\hline
\end{tabular}

Table 4: Frequency distribution of risk factors of participants (second interview after 6 months)

\begin{tabular}{|c|c|}
\hline Risk factors of participants & Frequency $(\mathrm{n}, \%)$ \\
\hline Smoking & $4848 \%$ \\
\hline Hypertension Stabilized & $7474 \%$ \\
\hline Regular Health Checkup & $8080 \%$ \\
\hline Stress in Family & $3232 \%$ \\
\hline No Exercise & $2222 \%$ \\
\hline Healthy Nutrition & $5555 \%$ \\
\hline
\end{tabular}

Table 5: 95\% CI and p-value of risk factors of participants

\begin{tabular}{|c|c|}
\hline Risk factors of participants & $95 \%$ CI $p$ value \\
\hline Smoking & $1.055-1.738<0.05$ \\
\hline Hypertension Stabilized & $0.678-1.00 \leq 0.05$ \\
\hline Regular Health Checkup & $0.179-0.392<0.05^{*}$ \\
\hline Stress in Family & $0.861-1.815>0.05^{*}$ \\
\hline No Exercise & $1.791-4.015<0.05^{*}$ \\
\hline Healthy Nutrition & $0.493-0.918<0.05$ \\
\hline
\end{tabular}

There were significant statistically differences between the responses in the first test and the second test referred to: smoking[95\% CI: 1.055-1.738, $p<0.05]$, hypertension stabilized[95\% CI: $0.678-1.00, \quad p \leq 0.05]$, regular health checkup [95\% CI: $0.179-0.392, \quad p<0.05], \quad$ stress in family [95\% CI: $0.861-1.815, p>0.05]$, no exercise $[95 \% C I$ : $1.791-4.015, p<0.05]$ and healthy nutrition[95\% CI: $0.493-$ $0.918, p<0.05]$.

Both women and men evidenced significant improvements in their diet, exercise, blood pressure, quality of life and stress management practices, which they maintained over the 6 months of the study.

\section{Discussion}

The lack of a multidisciplinary approach is certainly among the causes of the ineffectiveness of intervention in the field of cardiovascular secondary prevention.

In particular, people working in the nursing area can play a very important role which can be summed up into three different levels: a technical level, aiming at the cooperation with cardiologists to carry out diagnostic examinations and give a portrait of patients in terms of risks; a second level consists in giving information, and helping to face the disease, as well as stepping in during its evolution, almost a health counsellor for the patients; finally the nurse can act as a psychological support both to the patient and his/her family during acute illnesses and reassure him/her that he/she is being treated properly and that successively will resume a good quality of life. The staff of ambulatories should comprise a cardiologist and a trained professional nurse, this being specialized, specifically, in cardiology and cardiovascular prevention ${ }^{[17,18]}$

We have noted that in our study was a reduction in the number of patients who were smokers. We need to note that, at the time that we developed this study, there has been a strengthening of the law against smoking in our country. So, both of these activities, such as education of patients and law enforcement have affected the outcome that we presented.

Similarly needs to be clarified as a result of the intervention of the Ministry of Health regarding the check- up -in free, we received a significant increase in the number of patients who was "aware" and did regularly perform tests.

If we refer to stress in the family or in the daily life of our results are not significant because not all the stresses of daily life can be managed by the patient.

Daily life in our country, a country with low economic development, contains many personal and family stress, and it is difficult to be managed by the patient himself. A total change of the whole society and economic balance of the country will bring us the results that we want.

If refer to the "no exercise" does not mean that these patients did not receive a physical activity, but it has been minimal and for this reason they have been placed in this group $[22 \%]$.

As a summary of our discussions have brought the conclusion of the authors explicitly review Cochrein 2011 


\section{International Journal of Science and Research (IJSR) \\ ISSN (Online): 2319-7064}

Index Copernicus Value (2013): 6.14 | Impact Factor (2014): 5.611

"Implications for practice

Our findings are consistent with the belief that educational interventions are beneficial for patients with CHD. Further research is needed to determine the most effective and costeffective format, duration, timing (relative to index event) and methods of education delivery.

In accordance with current evidence and international guidelines for secondary prevention and $C R$, educational interventions for CHD patients should be considered as part of a comprehensive programme that includes exercise and psychological support" "[19].

\section{Conclusions}

There is a lack of good level of knowledge among patients after an acute cardiac event. Implementing aggressive educational strategies is of utmost importance in Albanian population for preventing the rising prevalence of these diseases.

\section{Relevance to Clinical Practice}

This pilot study has indicated that a patient-centre educating is beneficial and is associated with an improvement in patients' knowledge and self-care abilities. Healthcare professionals should utilize all educational resources specifically designed to the educational needs of these patients.

\section{References}

[1] Reddy KS, Yusuf S. Emerging epidemic of cardiovascular disease in developing countries. Circulation 1998;97:596-601.

[2] World Health Organization. Disease Statistics World Helath Report. Mortality by sex, cause and WHO Regions, Estimates for 19981999.

[3] Pais P, Pogue J, Gerstein H, Zachariah E, Savitha D, Jayprakash S, et al. Risk factors for acute myocardial infarction in Indians: a case-control study. Lancet 1996; 348:358-63.

[4] Krumholz HM, Amatruda J, Smith GL, Mattera JA, Roumanis SA, Radford MJ, et al. Randomized trial of an education and support intervention to prevent readmission of patients with heart failure. J Am Coll Cardiol 2002; 39:83-9.

[5] Abdelmoneim Awad and Hala Al-Nafis. Public knowledge of cardiovascular disease and its risk factors in Kuwait: a cross-sectional survey. BMC Public Health 2014, 14:1131

[6] ACC/AHA 2009 Guideline Update for the Diagnosis and Management of Chronic Heart Failure in the Adult. CIRCULATIONAHA.109.192064.

[7] HFSA 2010 Comprehensive Heart Failure Practice Guideline: Section 8: Disease Management, Advance Directives, and End-of-Life Care in Heart Failure Education and Counseling.

[8] Beckie Th, Beckstead J. Predicting Cardiac Rehabilitation Attendance In A Gender-tailored Randomized Clinical Trial J Cardiopulm Rehabil Prev. 2010 M; 30(3): 147-156.
[9] Antúnez de la Rosa Mdel R, Jiménez y Villegas Mdel C. Nurses' participation in heart rehabilitation. Arch Cardiol Mex. 2002;72 Suppl 1:S247-53

[10] Kamran S, Bener AB, Deleu D, Khoja W, Jumma M, Al Shubali A, Inshashi J, Sharouqi I, Al Khabouri J: The level of awareness of stroke risk factors and symptoms in the Gulf Cooperation Council countries: Gulf Cooperation Council stroke awareness study. Neuroepidemiology 2007, 29:235-242.

[11] Cooper et al., 2000Cooper, R., Cutler, J., DesvigneNickens, P., Fortmann, S.P., Friedman, L., Havlik, R., and Thom, T. Trends and disparities in coronary heart disease, stroke and other cardiovascular diseases in the United States. Circulation. 2000; 102: 3137-3147.

[12] Potvin L, Richard L, Edwards AC. Knowledge of cardiovascular disease risk factors among the Canadian population: relationships with indicators of socioeconomic status. CMAJ 2000,162(9 Suppl):S5-11.

[13]Bani IA, Hashim TJ. Knowledge of nutrition and coronary heart disease in Riyadh, Saudi Arabia. J Community Health 1999;24:467-73.

[14] Mukattash TL, Shara M, Jarab AS, Al-Azzam SI, Almaaytah A, Al Hamarneh YN: Public knowledge and awareness of cardiovascular disease and its risk factors: a cross-sectional study of 1000 Jordanians. Int J Pharm Pract 2012, 20:367-376.

[15] Khan MS, Jafary FH, Jafar TH, Faruqui AM, Rasool SI, Hatcher J, et al. Knowledge of modifiable risk factors of heart disease among patients with acute myocardial infarction in Karachi, Pakistan: a cross sectional study. BMC Cardiovascular Disorders 2006;6:18.

[16] Kerzman H, Baron-Epel O, Toren O. What do discharge patients know about their medication? Patient Educ Couns 2005; 56(3):276-82.

[17] Olga Kadda, Christina Marvaki, Demosthenes Panagiotakos. The role of nursing education after a cardiac event. Health Science Journal 2012; Volume 6 , Issue 4:634-647.

[18] Riccio C, Sommaruga M, Vaghi P, Cassella A, Celardo $\mathrm{S}$, Cocco $\mathrm{E}$, et al. Nursing role in cardiac prevention. Monaldi Arch Chest Dis. 2004;62(2):105-13.

[19] Brown JP, Clark AM, Dalal H, Welch K, Taylor RS. Patient education in the management of coronary heart disease. Cochrane Database Syst Rev. 2011 Dec 7: (12): CD008895. 